Supplement of Biogeosciences, 13, 4343-4357, 2016

http://www.biogeosciences.net/13/4343/2016/

doi:10.5194/bg-13-4343-2016-supplement

(C) Author(s) 2016. CC Attribution 3.0 License.

(c) (i)

Supplement of

\title{
Patterns of carbon processing at the seafloor: the role of faunal and mi- crobial communities in moderating carbon flows
}

Clare Woulds et al.

Correspondence to: Clare Woulds (c.woulds@leeds.ac.uk)

The copyright of individual parts of the supplement might differ from the CC-BY 3.0 licence. 

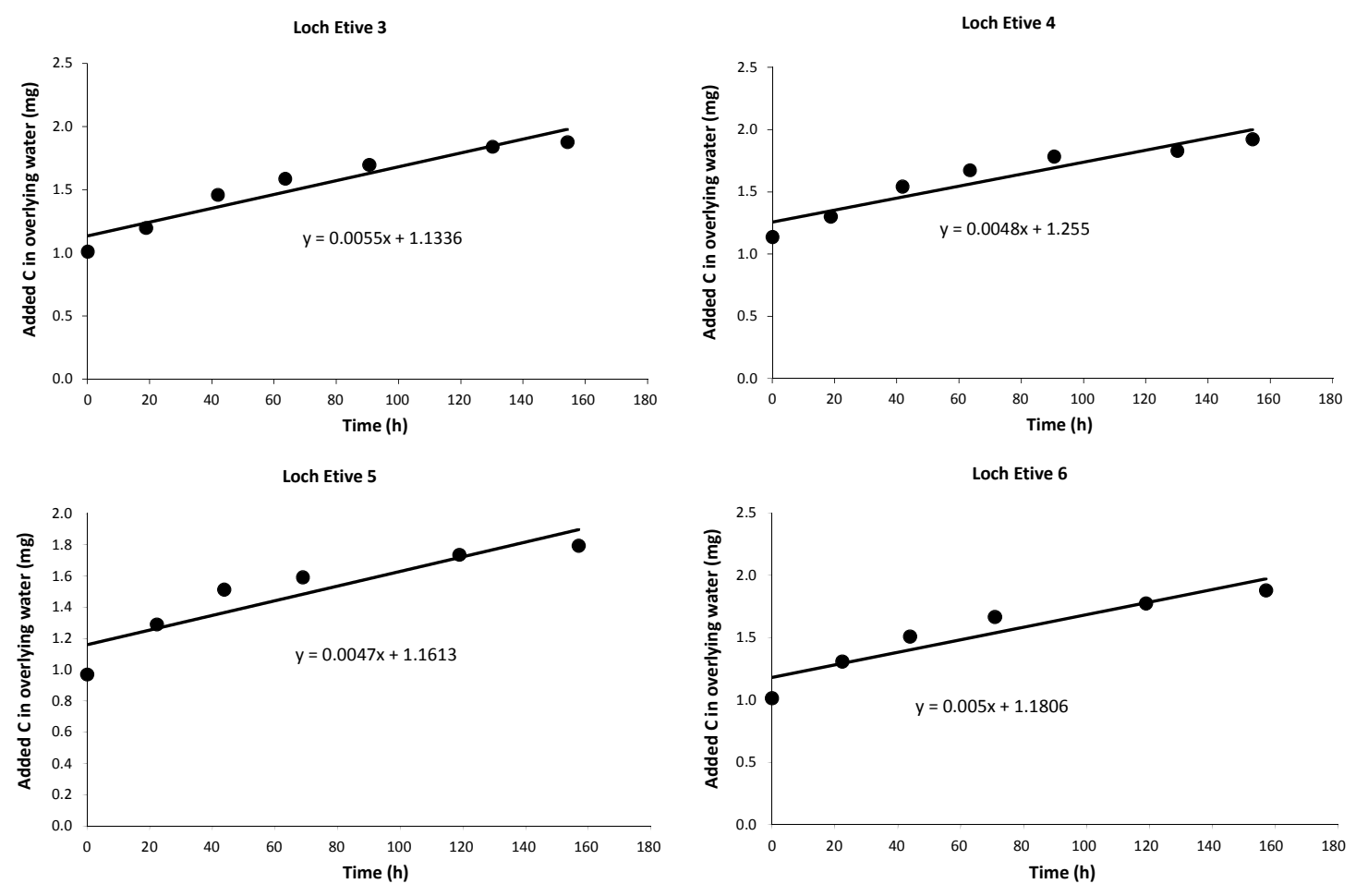

2

A
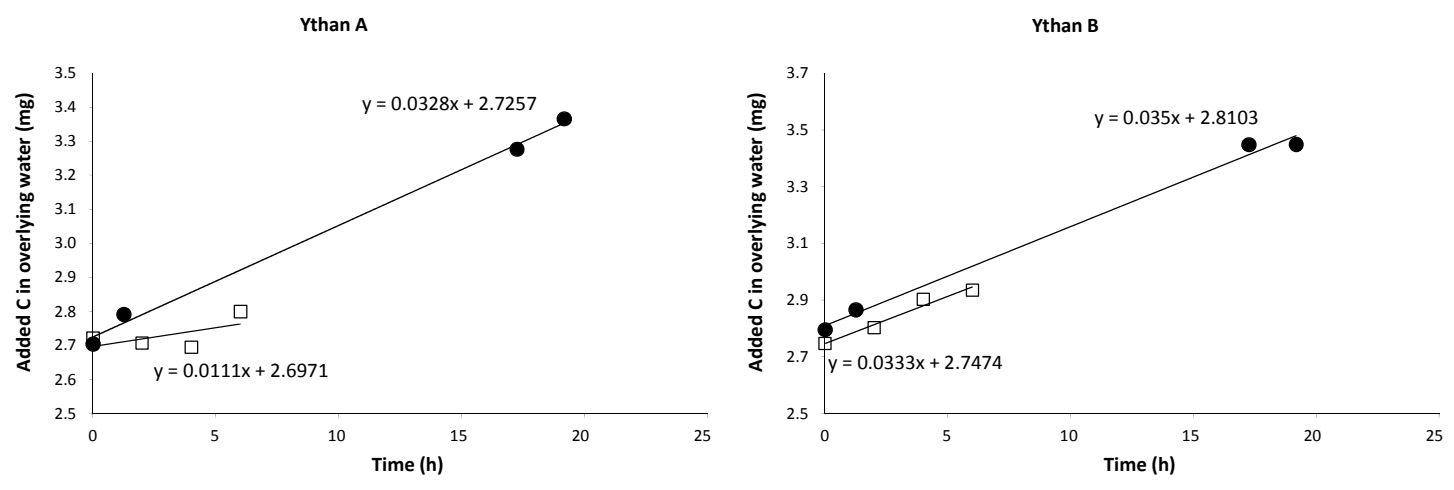

Ythan C

Ythan D
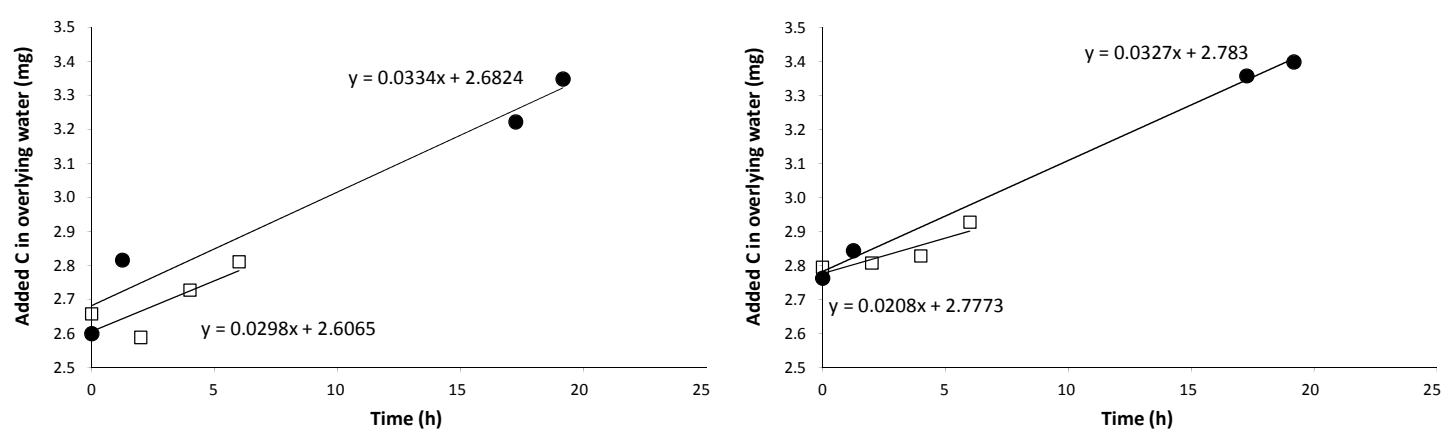
6 Figure S1. Quantity of added C over time in experimental chamber water columns, with regression lines 7 and equations used for calculating respiration rates, for a) Loch Etive and b) the Ythan sand flat. Note 8 that the chamber surface area was different for the two study sites (see methods). 